\title{
Strain differences in the amphibian chytrid Batrachochytrium dendrobatidis and non-permanent, sub-lethal effects of infection
}

\author{
Richard W. R. Retallick ${ }^{1,2, *}$, Verma Miera ${ }^{1}$ \\ ${ }^{1}$ School of Life Sciences, Arizona State University, PO Box 874501, Tempe, Arizona 85287-4501, USA \\ ${ }^{2}$ Present address: GHD Pty Ltd, Level 8, 180 Lonsdale Street, Melbourne, Victoria 3000, Australia
}

\begin{abstract}
The chytrid fungus Batrachochytrium dendrobatidis $(B d)$ is likely the cause of numerous recent amphibian population declines worldwide. While the fungus is generally highly pathogenic to amphibians, hosts express a wide range of responses to infection, probably due to variation among hosts and environmental conditions, but possibly also due to variation in $B d$. We investigated variation in $B d$ by exposing standardized host groups to $2 B d$ strains in a uniform environment. All exposed frogs became infected, but subsequent lethal and sub-lethal (weight loss) responses differed among groups. These results demonstrate variation in $B d$ and suggest variation occurs even at small geographical scales, likely explaining some of the variation in host responses. With lower than expected mortality among infected frogs, we continued our study opportunistically to determine whether or not frogs could recover from chytridiomycosis. Using heat, we cleared infection from half of the surviving frogs, leaving the other half infected, then continued to monitor mortality and weight. Mortality ceased among disinfected frogs but continued among infected frogs. Disinfected frogs gained weight significantly more than infected frogs, to the point of becoming indistinguishable from controls, demonstrating that at least some of the effects of sub-lethal chytridiomycosis on hosts can be non-permanent and reversible.
\end{abstract}

KEY WORDS: Batrachochytrium dendrobatidis - Strains · Amphibians · Sub-lethal infection · Mortality $\cdot$ Recovery

Resale or republication not permitted without written consent of the publisher

\section{INTRODUCTION}

The chytrid fungus Batrachochytrium dendrobatidis $(B d)$ is most likely the cause of recent, rapid declines among amphibian populations around the world (Berger et al. 1998, Daszak et al. 1999, Stuart et al. 2004, Lips et al. 2006). Since the discovery of $B d$ (Berger et al. 1998, Longcore et al. 1999), numerous strains have been isolated from a range of hosts around the world (Longcore et al. 1999, Morehouse et al. 2003). Those strains have been used subsequently to infect hosts in laboratories in an effort to understand variation in the impact, natural history, and ecology of $B d$ (e.g. Johnson et al. 2003, Wood- hams et al. 2003, Berger et al. 2004, Briggs et al. 2005).

Host responses to $B d$ infection vary widely in nature and in the laboratory. Some individuals of some species become infected, and some infected individuals die (Lips 1999, Bradley et al. 2002, Retallick et al. 2004, Lips et al. 2006). Death may be rapid or slow (Berger et al. 1998). Some amphibians may clear infection under favorable conditions (Woodhams et al. 2003), while others persist with infection for long periods apparently unaffected (Daszak et al. 2004). The range of responses can be explained by variation in any of host resistance, pathogen virulence and environmental conditions. Accepting that 
variation occurs among hosts and among environments, and given the broad, global host range of $B d$ (Speare \& Berger available at www.jcu.edu.au/ school/phtm/PHTM/frogs/chyspec.htm), we asked the question: do standardized host groups respond in the same way when exposed to different strains of $B d$ under uniform laboratory conditions?

Subsequently, with higher than expected survival of infected frogs and marked sub-lethal effects, we continued our study opportunistically to determine whether frogs could regain their health if their infection is cleared. Until now, most studies have focused on mortality caused by $B d$, but increasing numbers of amphibian populations have been found to host endemic Bd infections (Retallick et al. 2004, Garner et al. 2005, McDonald et al. 2005), suggesting that the long-term persistence and success of populations may be determined also by the impact of sub-lethal effects. And, because little is known about how $B d$ kills or degrades the health of its hosts, understanding the potential for reversal of the effects of chytridiomycosis on an individual may help to eliminate potential causes of death.

The first part of our study is remarkably similar to the study by Berger et al. (2005). Because the studies were conducted in geographically distant locations almost concurrently, using different $B d$ strains and amphibian hosts, and each was conducted with no knowledge of the other, they provide independent, parallel tests of the same hypothesis. Given the global range of infected hosts and environments, the $B d$ host-pathogen system is likely to be highly variable, and experimental results from one location may differ from those in others. We suggest a comparative approach, such as that enabled by this study and that of Berger et al. (2005), is essential for understanding variation in the ecology of $B d$ in nature.

\section{MATERIALS AND METHODS}

We isolated and maintained $B d$ from 2 western chorus frogs Pseudacris triseriata collected from sites within $50 \mathrm{~km}$ of each other on the Mogollon Rim in Arizona, USA. One strain was isolated by E. W. Davidson on 2 May 2001 from a frog collected from 27-Mile Lake by S. Blomquist (Arizona Game and Fish Department) on 27 April 2001. This particular frog was collected alive, but showed signs (slight lethargy and sloughing) that suggested it may have had chytridiomycosis. Dead P. triseriata frogs had been observed by Arizona Game and Fish Department staff at the same site on an earlier occasion. The second strain was isolated by V. Miera on 8 July 2004 from a frog collected alive from Lost Lake by V. Miera on 24 September 2003. While this frog appeared healthy when captured, and no dead frogs were observed at Lost Lake at the time of collection, the frog was sloughing skin, which suggested it may have had chytridiomycosis. Upon returning to the laboratory, we examined the sloughed skin under a phase contrast light microscope (200× magnification) and observed $B d$ sporangia. Both frogs were kept isolated (i.e. in separate containers) from all other frogs from the time of collection to the time of $B d$ isolation. The 27-Mile Lake frog died in the laboratory and $B d$ was isolated within days of death. The Lost Lake frog died in the laboratory on 4 July 2004, and Bd was isolated successfully on 8 July 2004. After death, the carcasses of both frogs were kept in separate containers at $4^{\circ} \mathrm{C}$ until $B d$ had been isolated.

Each strain was isolated on mTGHL (8 g tryptone, $2 \mathrm{~g}$ gelatin hydrolysate, $4 \mathrm{~g}$ lactose, $10 \mathrm{~g}$ agar, and $1000 \mathrm{ml}$ distilled $\mathrm{H}_{2} \mathrm{O}$ ), then maintained in a TGHL broth (16 g tryptone, $4 \mathrm{~g}$ gelatin hydrolysate, $2 \mathrm{~g}$ lactose, $10 \mathrm{~g}$ agar, and $1000 \mathrm{ml}$ distilled $\mathrm{H}_{2} \mathrm{O}$ ) in a $25 \mathrm{ml}$ tissue flask at $10^{\circ} \mathrm{C}$ and passed every few weeks under sterile conditions. For each passage, $2 \mathrm{ml}$ of broth was extracted from the active culture and added to $10 \mathrm{ml}$ of fresh TGHL in a new tissue culture flask. Prior to its use in this study, the 27-Mile Lake isolate had been passed a minimum of 60 times, while the Lost Lake isolate had been passed fewer than 10 times.

Using uniform husbandry, we reared 60 Pseudacris triseriata frogs in the laboratory from 4 egg masses collected from 27-Mile Lake in Spring 2003. Each frog was assigned to one of 3 groups, each containing 20 frogs, with care taken to mix clutches equally to minimize clutch bias. On 1 November 2004, we inoculated one group with $B d$ zoospores from 27-Mile Lake and another group with zoospores from the Lost Lake strain. As a control, we inoculated the third group of frogs with 27-Mile Lake zoospores that had first been autoclaved (i.e. killed) and cooled. To obtain zoospores for inoculation, freshly passed cultures were left at a relatively constant room temperature of approximately $20^{\circ} \mathrm{C}$ for $3 \mathrm{~d}$ before all supernatant was removed, leaving only $B d$ sporangia attached to the walls of the empty flasks. Approximately $50 \mathrm{ml}$ of a dilute saline solution (DS) (Boyle et al. 2003) was then added to each flask, causing the sporangia to release zoospores into the DS. The flasks were ready for use the next day. To estimate $B d$ concentration, zoospores from each culture were counted using a haemocytometer immediately before inoculation. Depending on zoospore density, we made 3 to 10 counts within $1 \mathrm{~mm}^{2}$ sections, then multiplied the mean count by $10^{4}$ to estimate zoospore concentration per $\mathrm{ml}$. We standardized zoospore numbers by diluting the strain with the larger count so that it matched the strain with the smaller count. 
For inoculation, we placed frogs individually in $600 \mathrm{ml}$ Ziploc $^{\circledR}$ (SC Johnson) plastic containers with $100 \mathrm{ml}$ of aged tap water, and then immediately afterwards we added $2 \mathrm{ml}$ of inoculum to the water in each container. All frogs were kept with the inoculum for $24 \mathrm{~h}$ and immersed periodically to increase the likelihood of infection, before being moved to a new set of 60 clean containers. One week later we repeated the entire inoculation procedure, including zoospore counts and standardization, to further increase the likelihood of infection. The 2 inoculations contained approximately $4 \times 10^{4}$ zoospores $\mathrm{ml}^{-1}$ and $6 \times 10^{4}$ zoospores $\mathrm{ml}^{-1}$, respectively (total zoospores added: $8 \times 10^{4}$ and $1.2 \times 10^{5}$, respectively).

Before and after inoculation, frogs were kept at a relatively constant room temperature $\left(\sim 20^{\circ} \mathrm{C}\right)$, housed individually in 1.9 l Glad $^{\circledR}$ 'Deep Dish' plastic containers (The Clorox Company) with moistened disposable paper towels. Each week, containers were changed, paper towels were renewed, and frogs were fed (small crickets with occasional vitamin supplements). After inoculation, we checked frogs daily for typical signs of chytridiomycosis (Berger et al. 1998).

To determine their $B d$ infection status, all frogs were sampled for $B d 3$ times: (1) before inoculation to verify that no frogs were infected prior to inoculation; (2) after $16 \mathrm{~d}$ to confirm infection in treatment individuals; (3) after death for frogs that died or after $93 \mathrm{~d}$ for frogs that survived, to determine persistence of infection at the conclusion of the experiment. Sampling was performed by gently stroking flat wooden toothpicks (see Retallick et al. 2006) across the toes, webbing, feet, thighs, sides and abdomen of the frogs (Briggs \& Vredenberg available at http://amphibiaweb.org/ chytrid/swab_instruction.pdf, Livo 2004 at http:// wildlife.state.co.us/NR/rdonlyres/710BBC95-2DCF4CF9-8443-D4561 DBC3B 69/0/PCRsampling2004.pdf), with a minimum of 20 strokes per individual. Toothpicks were then stored in $2 \mathrm{ml}$ Axygen screw-cap tubes (with rubber o-rings) filled with $1 \mathrm{ml} 70 \%$ ethanol. $\mathrm{Bd}$ was detected on toothpicks using quantitative PCR (Boyle et al. 2003), following the specific methodology described by Retallick et al. (2006). Frogs were measured (snout-vent length SVL) and weighed before inoculation, then re-weighed after 43 and $93 \mathrm{~d}$. To minimize $B d$ cross-contamination, we used disposable latex gloves to handle frogs (single use) and disinfected (using $\sim 20 \%$ bleach), rinsed and dried all containers before re-use.

Some frogs survived with infection longer than expected, so we continued our study opportunistically. Ninety-three days after inoculation, we placed all frogs into separate, clean containers with new, moistened paper toweling. Then we placed some of the surviving frogs (in their containers) from each infected group into an incubator for $5 \mathrm{~d}$ at $32^{\circ} \mathrm{C}$, to clear their $\mathrm{Bd}$ infection (Johnson et al. 2003). Two of the 4 frogs that survived with Lost Lake $B d$ and 5 of the 12 frogs that survived with 27-Mile Lake $B d$ were treated. Five of 20 controls were also placed in the incubator to gauge the effect of the disinfection treatment. All remaining frogs were kept at laboratory room temperature $\left(\sim 20^{\circ} \mathrm{C}\right)$. After incubation, weekly feeding and changes of containers and toweling were resumed for all surviving frogs. Frogs were then weighed on Days 172 and 257 and sampled for $B d$ (as described above) on Day 172 to confirm the long-term success of the disinfection treatment. We then compared weights of infected and uninfected groups over time to measure host recovery after infection was cleared.

Differences among groups in initial SVL, initial weight, change in weight after $43 \mathrm{~d}$, and change in weight after $93 \mathrm{~d}$ were tested using ANOVA, with Tukey's Honestly Significant Difference (HSD) posthoc comparisons. Differences in mortality among groups were tested using survival analysis (KaplanMeier method, Mantel log-rank test). That analysis was then repeated without controls to determine the difference between infected groups. Two-sample $t$-tests were used to determine differences in initial weight and SVL for frogs that survived and frogs that died on or before Day 93. That analysis was then repeated separately for frogs infected with each strain. Using a $t$-test, weight changes in infected frogs that were incubated were compared with those in frogs that retained infection. One frog escaped from the Lost Lake $B d$ group on Day 16 and this individual was included only in comparisons of initial SVL and weight. All statistical analyses were performed using SYSTAT 10.2.01 (SYSTAT Software).

\section{RESULTS}

No frogs hosted $B d$ before inoculation. With inoculation, all frogs exposed to $B d$ became infected and all controls remained uninfected. After inoculation, no infected frogs cleared infection naturally and no controls became infected.

$B d$ strains caused different patterns in host mortality. Of 20 frogs infected with 27-Mile Lake $B d, 5$ died within $19 \mathrm{~d}$ of the first inoculation and 3 more died between Days 78 and 93. Twelve frogs survived with infection to the end of the experiment (93 d after first inoculation). Of the frogs infected with Lost Lake $B d$, none died within the first $18 \mathrm{~d}$, then 15 died between Days 19 and 70. Four survived with infection. One frog escaped after $16 \mathrm{~d}$ and was not recovered. No controls died during the experiment. Survival analysis showed that the groups' responses were significantly different 
(controls included: $\chi^{2}=25.782, \mathrm{df}=2, \mathrm{p}<0.001$; controls excluded: $\chi^{2}=5.323$, df $=1, \mathrm{p}=0.021$ ) (Fig. 1 ).

Before inoculation, controls were on average $0.8 \mathrm{~mm}$ $(3.7 \%)$ larger than the other groups, which was marginally significant, but frogs in all groups were similar in weight (Tables $1 \& 2$ ). After inoculation, both chytrid strains caused significant deterioration in the condition of frogs. After $43 \mathrm{~d}$, infected frogs weighed on average $0.21 \mathrm{~g}(25.7 \%)$ less than controls, and frogs infected with Lost Lake $B d$ weighed on average $0.12 \mathrm{~g}(16.0 \%)$ less than frogs infected with the 27-Mile Lake strain (Fig. 2). After 93 d, infected frogs weighed on average $0.34 \mathrm{~g}(41.8 \%)$ less than controls, and frogs infected with Lost Lake $B d$ weighed on average $0.12 \mathrm{~g}(15.1 \%)$ more than frogs infected with 27-Mile Lake $B d$ (Fig. 2). Infected frogs lost up to $50 \%$ of their initial weight. When compared with the frogs' initial weights, those changes in weight differed significantly among all 3 groups at $43 \mathrm{~d}$, and between infected frogs and con-

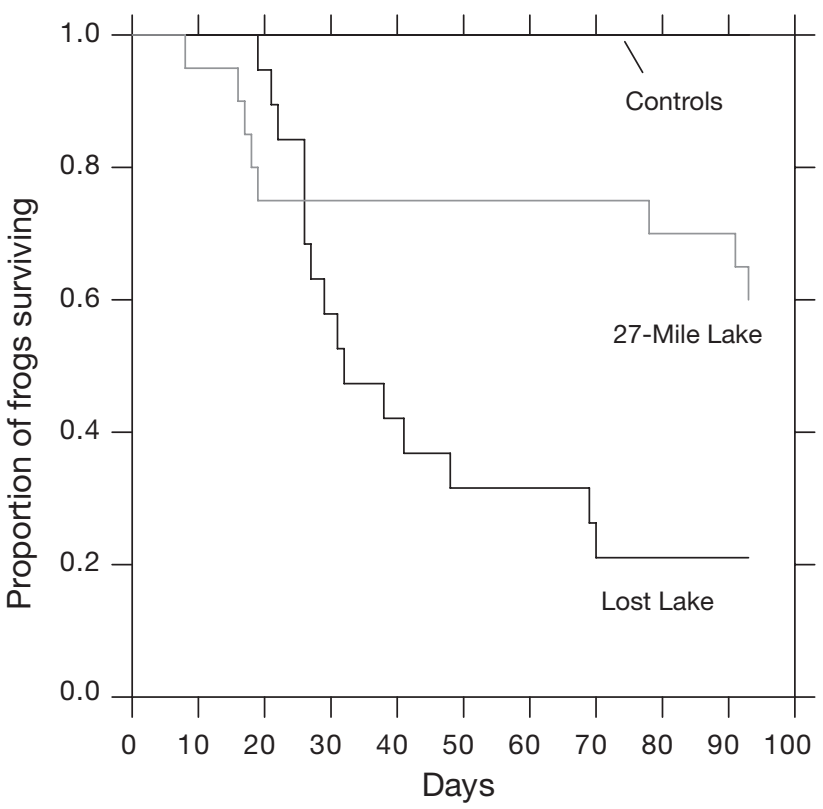

Fig. 1. Pseudacris triseriata. Survival curves for frogs infected with $B d$ strains from 27-Mile Lake and Lost Lake and for controls (no mortality; line follows $y=1$ ). One frog infected with 27-Mile Lake $B d$ escaped during the experiment and has been omitted

Table 1. Pseudacris triseriata. Sizes and weights of frogs in each group at the beginning of the experiment (i.e. initial weight and snout-vent lengths, SVL, before inoculation)

\begin{tabular}{|lccccc|}
\hline \multirow{2}{*}{ Group } & \multirow{2}{*}{$\mathrm{n}$} & \multicolumn{2}{c}{ Weight (g) } & \multicolumn{2}{c|}{ SVL (mm) } \\
& & Mean & SD & Mean & SD \\
\hline Lost Lake & 20 & 0.83 & 0.11 & 21.60 & 1.14 \\
27-Mile Lake & 20 & 0.84 & 0.14 & 21.70 & 1.13 \\
Controls & 20 & 0.90 & 0.11 & 22.45 & 1.23 \\
\hline
\end{tabular}

trols, but not between the 2 infected groups, at $93 \mathrm{~d}$ (Table 2).

Initial SVLs of frogs that died from infection during the experiment were similar to those of frogs that survived with infection. However, frogs that died weighed significantly less initially ( $t=2.667, \mathrm{df}=37, \mathrm{p}=0.011$ ). Frogs that died weighed $0.79 \pm 0.11 \mathrm{~g}$ (mean $\pm \mathrm{SD}, \mathrm{n}=$ 23) initially, while frogs that survived weighed $0.89 \pm$ 0.13 ( $\mathrm{n}=16$ ) initially. Investigation of each strain separately showed that the initial weight difference among frogs prevailed for 27-Mile Lake $B d(t=2.244$, $\mathrm{df}=18$, $\mathrm{p}=0.038)$ but not for Lost Lake $B d(t=1.323, \mathrm{df}=17$, $\mathrm{p}=0.203)$.

Incubation for $5 \mathrm{~d}$ at $32^{\circ} \mathrm{C}$ cleared $\mathrm{Bd}$ from all infected frogs. Two frogs infected with 27-Mile Lake $B d$ and one infected with Lost Lake $B d$ died in the incubator (Table 3), but none died thereafter. All infected frogs not subjected to the incubation retained infection. Four of the 5 frogs infected with 27-Mile Lake Bd died on Days $122,123,162$, and 230. One frog infected with 27-Mile Lake $B d$ and both frogs infected with Lost Lake $B d$ survived with infection until the study ended on Day 257. No controls died during or after the incubation.

After Day 93, frogs whose infection was cleared increased in weight significantly more than frogs that retained infection (i.e. that were not incubated) $(t=6.020$, $\mathrm{df}=7, \mathrm{p}=0.001$; strains grouped to maximize statistical power; controls omitted) (Fig. 2). Frogs in all groups increased in weight until Day 172, but after that, infected frogs decreased in weight markedly (Fig. 2). Between Days 93 and 257, every individual that cleared infection gained weight, while every individual but one that retained infection lost weight. The sole surviving frog from the disinfected Lost Lake group (Fig. 2: Lost Lake $32^{\circ} \mathrm{C}$ ) increased in weight so dramatically that it was indistinguishable from controls at the end of the study.

\section{DISCUSSION}

Two groups of Pseudacris triseriata showed different lethal and sub-lethal responses to infection with 2 strains of $B d$. That result was unlikely to have been influenced by variation among hosts or environmental conditions, because we conducted our experiment using genetically and developmentally similar frogs in an equal and controlled environment. Therefore, we attribute different responses to variation in $B d$.

Part of our study considers mortality and is remarkably similar in methodology and outcome to the study by Berger et al. (2005). Similarity between the 2 studies' results suggest strain differences are common for $B d$ and must be considered by all researchers working with this host-pathogen system. Differences between the studies, however, highlight important issues that may not have 
Table 2. Pseudacris triseriata. ANOVA results for initial weight and snout-vent lengths (SVL), and changes in weight for frogs during the experiment. Tukey's Honestly Significant Difference (HSD) was used for post-hoc comparisons (>: significant difference). C: Controls, 27M: 27-Mile Lake, LL: Lost Lake

\begin{tabular}{|llrrrr|}
\hline Variable & Time & $F$ & df & p & \multicolumn{1}{c|}{$\begin{array}{c}\text { Post-hoc } \\
\text { comparisons }\end{array}$} \\
\hline Weight & Start of expt. & 1.928 & 2,57 & 0.155 & C $=27 \mathrm{M}=$ LL \\
SVL & Start of expt. & 3.157 & 2,57 & 0.050 & C $>27 \mathrm{M}=$ LL \\
Change in weight & After 43 d & 31.578 & 2,39 & $<0.001$ & $\mathrm{C}>27 \mathrm{M}>$ LL \\
Change in weight & After 93 d & 70.154 & 2,34 & $<0.001$ & $\mathrm{C}>27 \mathrm{M}=\mathrm{LL}$ \\
& & & & & \\
\hline
\end{tabular}

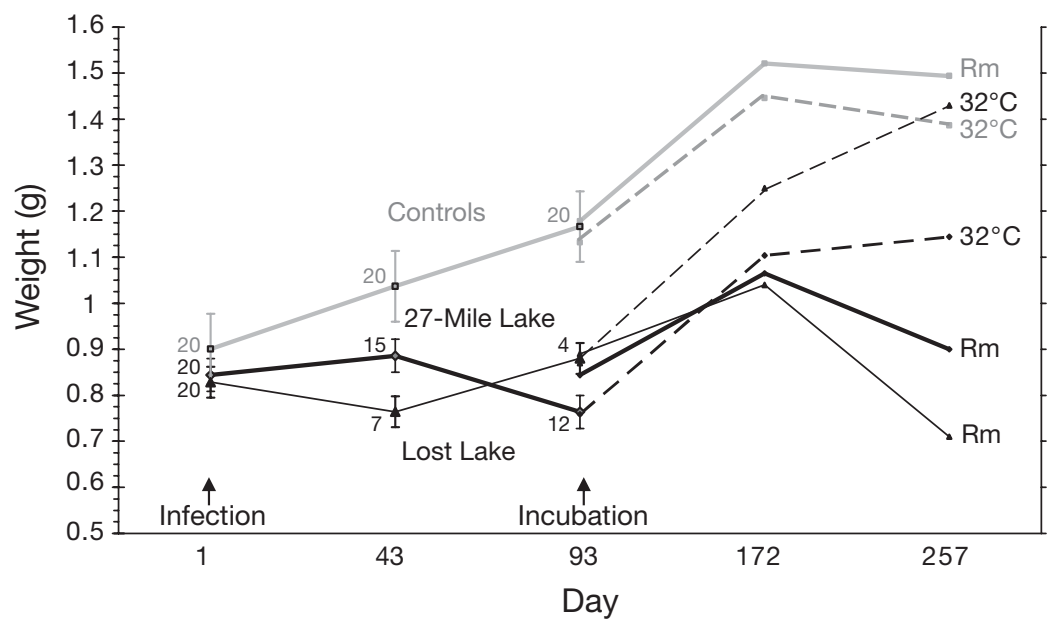

Fig. 2. Pseudacris triseriata. Mean weight of frogs in each experimental group during the study period. Frogs were placed in 3 groups until the incubation treatment (Day 93), after which each group was split into 2. Means \pm SE (with sample sizes indicated adjacent to each mean) shown until the incubation treatment. SE and sample sizes omitted thereafter for clarity. (Note: sample sizes for groups after Day 93 are presented in Table 3.) Broken lines and $32^{\circ} \mathrm{C}$ indicate groups that were incubated. Unbroken lines and room temperature $(\mathrm{Rm})$ indicate those that were not. $x$-axis is not to scale

Table 3. Pseudacris triseriata. Mortality of frogs beyond Day 93, after which some were incubated for $5 \mathrm{~d}$ at $32^{\circ} \mathrm{C}$ to clear $B d$ infection. Infection status at Day 172 shows that incubation was successful. In the 27-Mile Lake group that was not incubated, 2 frogs survived until Day 172, but one of these died before the end of the study at Day 257

\begin{tabular}{|c|c|c|c|c|c|c|}
\hline $\begin{array}{l}\text { Incubation } \\
\text { at } 32^{\circ} \mathrm{C}\end{array}$ & Group & $\mathrm{n}$ & $\begin{array}{l}\text { Deaths in } \\
\text { incubator }\end{array}$ & $\begin{array}{l}\text { Deaths after } \\
\text { incubation } \\
\text { period }\end{array}$ & $\begin{array}{l}\text { Number } \\
\text { infected at } \\
\text { Day } 172\end{array}$ & $\begin{array}{c}\text { Number } \\
\text { alive at } \\
\text { Day } 257\end{array}$ \\
\hline \multirow[t]{3}{*}{ Yes } & Lost Lake & 2 & 1 & 0 & 0 & 1 \\
\hline & 27-Mile Lake & 7 & 2 & 0 & 0 & 5 \\
\hline & Controls & 5 & 0 & 0 & 0 & 5 \\
\hline \multirow[t]{3}{*}{ No } & Lost Lake & 2 & - & 0 & 2 & 2 \\
\hline & 27-Mile Lake & 5 & - & 4 & 2 (of 2) & 1 \\
\hline & Controls & 15 & - & 0 & 0 & 15 \\
\hline
\end{tabular}

surfaced had the studies not been so similar. Variation in $B d$ appears to affect the pathogen's impact in different ways. Where Berger et al. (2005) found strains varied in the rate they killed frogs, with the most recently isolated strain killing most quickly, we found strains differed in the numbers of frogs they killed, with the more recently isolated strain killing more. Berger et al. (2005) reported $100 \%$ mortality of infected frogs after $67 \mathrm{~d}$. Some frogs in our study survived with infection for at least $257 \mathrm{~d}$, nearly 4 times longer. These differences may be explained by differences in host resistance. Berger et al. (2005) infected Litoria caerulea, a species with no history of $B d$-related decline and relatively few observations of $B d$ infection in nature (Berger et al. 1998, Speare \& Berger available at: www.jcu.edu.au/ school/phtm/PHTM/frogs/ chyspec.htm). We used Pseudacris triseriata, a species known to be infected with $B d$ at numerous locations across North America (Ouellet et al. 2005), and which is known to have undergone mass mortality events due to $B d$ infection (Sredl et al. 2003). Historically, $P$. triseriata may have been exposed to $B d$ over a longer period than $L$. caerulea and, therefore, may have developed more resistance to infection. L. caerulea may be evolutionarily naïve to $B d$ infection and therefore more susceptible to the pathogen.

Differences in mortality may be explained also by differences in the pathogenicity of $B d$ strains. Berger et al. (2005) used 3 strains from Australia and we used 2 from Arizona. Australian strains may be more pathogenic than North American strains, although it is unclear why that might be so. The earliest reports of $B d$ in North America and Australia are 1961 and 1978 respectively (Speare \& Berger available at: www.jcu.edu.au/school/phtm/ PHTM/frogs/chyspec.htm, Ouellet et al. 2005). The $B d$ host-pathogen system may have evolved for longer in North America than in Australia and be closer to a balance where $B d$ persists as an endemic infection in some populations. If true, however, that regional pattern is not consistent because there 
is evidence that some populations in Australia also host endemic infection (Retallick et al. 2004, McDonald et al. 2005).

Differences between the inoculation methods of the studies may have influenced mortality rates. Frogs in both studies were inoculated with similar numbers of zoospores, but zoospores were applied in different concentrations. We added zoospores to $100 \mathrm{ml}$ of water, while Berger et al. (2005) added zoospores to $5 \mathrm{ml}$. Consequently, frogs in the 2 studies may have been infected initially by different numbers of zoospores, influencing the rate of $B d$ proliferation and each host's time to death (dose-response curve; Carey et al. 2006). Other differences between the studies seem unlikely to have influenced the results. In particular, the use of different techniques to detect $B d$ (Berger et al. 2005 used histology, we used PCR) did not influence the result, because both studies reported $100 \%$ infection rates.

Prolonged survival of some infected frogs allowed us to document sub-lethal effects of chytridiomycosis. While controls gained weight during the course of the study, all infected frogs lost weight. The gradual deterioration of the health of surviving infected frogs may indicate that $B d$ causes a chronic yet ultimately fatal infection in some animals, rather than a truly sub-lethal infection (i.e. $B d$ still kills its host, but over a long period of time). For simplicity, we categorize all non-lethal responses to $B d$ infection in this study as 'sub-lethal'. For animals raised in the laboratory with favorable, stable environments, sub-lethal effects may be relatively unimportant. In nature, however, pressures from predation, competition and environmental conditions may combine with sub-lethal effects to reduce the survival potential of infected hosts (Parris \& Baud 2004). In nature, some hosts that appear unaffected by $B d$ infection (e.g. Ambystoma tigrinum and Rana catesbeiana; Davidson et al. 2003, Garner et al. 2006, respectively) may suffer sub-lethal effects that pass undetected. $B d$ infection appears to cause inappetence (Berger et al. 2005), so amphibians that live with infection for extended periods may slowly starve. For amphibians of similar size, those with smaller energy reserves would likely starve earlier. That pattern fits our observations. Frogs that died from infection were initially lighter than frogs that survived, but for one strain only (Lost Lake strain). Why this pattern was not observed for both strains is unclear. Frogs from 27-Mile Lake may be better adapted to the 27-Mile Lake $B d$ than to the Lost Lake $B d$ such that the local strain kills only weak animals.

In Pseudacris triseriata, sub-lethal effects are nonpermanent and reversible. All infected frogs regained weight after their infection was cleared, to the point of becoming indistinguishable from controls. One infected frog lost $>12 \%$ of its body weight, all movement in its rear legs and was within days of death (based on our observations of other frogs that died during the study), yet recovered fully following heat treatment. Observations like this may help to shed light on the question of how $B d$ kills its host. For example, while chytridiomycosis changes the behavior of infected amphibians (Berger et al. 1998), those changes do not appear to result from irreversible damage to the neurological system. Whether a recovered host's longevity is reduced by sub-lethal infection is unknown.

$B d$ strain differences appear to be unrelated to geography and host taxonomy. Given the relative geographical proximity of collection sites for strains in Arizona compared with the Australian study, and the range of species from which strains were isolated, we would have expected less host-response variation between the Arizonan strains than among the Australian strains. The 3 Australian strains were isolated from different species from widely dispersed locations, and then applied to captive-reared frogs. We used strains isolated from one species in one area and infected frogs of the same species from the same area. Both studies, however, report marked differences in the effects of $B d$ strains. Dispersal of $B d$ and evolution of the $B d$ host-pathogen system require further work at all spatial scales.

As acknowledged by Berger et al. (2005), strain differences observed in experiments using cultured $B d$ may be attributed to attenuation of the pathogen's virulence. Selective pressures encountered by $B d$ in microbiological nutrient broths likely differ from those operating on and within amphibian skin, and may favor different evolutionary changes. Strains used by us and by Berger et al. (2005) were isolated 1.5 to 42 mo before use. Other fungi change in virulence during extended periods in culture (Butt \& Goettel 2000), and we have observed a gradual decrease in zoospore output in another, older $B d$ culture (V. Miera pers. obs.). If $B d$ attenuates in culture, then experimental results using aged cultures in the laboratory may not adequately describe host-pathogen relationships in nature. This has implications for our current understanding of $B d$ ecology, which is based primarily on laboratory-generated information. Whether or not $B d$ attenuates in culture, it appears capable of subtle and rapid evolutionary changes that significantly influence its impact on amphibian populations. Assuming those changes occur in all $B d$ isolates, they do not appear to be always detectable at a molecular level with currently available diagnostic tools (Morehouse et al. 2003). We caution investigators comparing the effects of $B d$ among multiple hosts or locations to first determine differences between strains, or to use a single isolate of $B d$.

We do not suggest here that variation in $B d$ accounts for all variation in the pathogen's impact in nature. There is evidence to suggest that both environmental and host variation influence the impact of 
Bd (Berger et al. 2004, Lips et al. 2006). We suggest that the impact of $B d$ worldwide is determined by a complex relationship between variation in $B d$, environment and host, the balance of which likely varies with location, host community, types of $B d$ present, and time. In populations where $B d$ becomes endemic, variable rates of co-evolution between $B d$ and hosts likely complicate the relationship further.

Acknowledgements. We thank K. Richards for PCR diagnosis and A. Hyatt and D. Boyle (AAHL, CSIRO, Geelong, Australia) for the qPCR protocol. R. Hobbs, J. Hernandez, K. Richards, $\mathrm{S}$. Cashins and O. Ruballos helped with animal care and J. Collins, E. Davidson, J. Brunner and D. Schock provided input and advice that improved this study. Funding was provided by Arizona Game and Fish Department, ASU, The Ford Foundation, and the NSF through the Integrated Research Challenges in Environmental Biology (IRCEB) program. This project was completed under permits from Arizona Game and Fish Department (Scientific Collecting Permit \#SP552271 to J. Collins) and Institutional Animal Care and Use Committee (IACUC) Animal Protocol Review (Protocol \#03-671R) to J. Collins, and a letter of permission from the Forest Service to V.M. (File Code 2720), approving collection for scientific purposes on Forest Service Land. We thank 2 anonymous reviewers for comments that improved the manuscript.

\section{LITERATURE CITED}

Berger L, Speare R, Daszak P, Green DE and 10 others (1998) Chytridiomycosis causes amphibian mortality associated with population declines in the rain forests of Australia and Central America. Proc Natl Acad Sci USA 95:9031-9036

Berger L, Speare R, Hines H, Marantelli G and 10 others (2004) Effect of season and temperature on mortality in amphibians due to chytridiomycosis. Aust Vet J 82:31-36

Berger L, Marantelli G, Skerratt LF, Speare R (2005) Virulence of the amphibian chytrid fungus Batrachochytrium dendrobatidis varies with the strain. Dis Aquat Org 68:47-50

Boyle DG, Hyatt AD, Daszak P, Berger L, Longcore JE, Porter D, Hengstberger SG, Olsen V (2003) Cryo-archiving of Batrachochytrium dendrobatidis and other chytridiomycetes. Dis Aquat Org 56:59-64

Bradley GA, Rosen PC, Sredl MJ, Jones TR, Longcore JE (2002) Chytridiomycosis in native Arizona frogs (Rana yavapaiensis, Rana chiricahuensis, and Hyla arenicolor). J Wildl Dis 38:206-212

Briggs CJ, Vredenburg VT, Knapp RA, Rachowicz LJ (2005) Investigating the population-level effects of chytridiomycosis: an emerging infectious disease of amphibians. Ecology 86:3149-3159

Butt TM, Goettel MS (2000) Bioassays of entomogenous fungi. In: Navon A, Ascher KRS (eds) Bioassays of entomopathogenic microbes and nematodes. CABI International Press, Wallingford, p 141-195

Carey C, Bruzgul JE, Livo LJ, Walling ML and 5 others (2006) Experimental exposures of boreal toads (Bufo boreas) to a pathogenic chytrid fungus (Batrachochytrium dendrobatidis). Ecohealth 3:5-21

Daszak PL, Berger L, Cunningham AA (1999) Emerging infectious diseases and amphibian population decline. Emerg Infect Dis 5:735-748
Daszak P, Strieby A, Cunningham AA, Longcore JE, Brown CC, Porter D (2004) Experimental evidence that the bullfrog (Rana catesbeiana) is a potential carrier of chytridiomycosis, an emerging fungal disease of amphibians. Herpet J 14:201-207

Davidson EW, Parris M, Collins JP, Longcore JE, Pessier AP, Brunner J (2003) Pathogenicity and transmission of chytridiomycosis in tiger salamanders (Ambystoma tigrinum). Copeia 2003(3):601-607

Garner TWJ, Walker S, Bosch J, Hyatt AD, Cunningham AA, Fisher MC (2005) Widespread European distribution of a global amphibian pathogen. Emerg Infect Dis 11: 1639-1641

Garner TWJ, Perkins MW, Govindarajulu P, Seglie D, Walker SF, Cunningham AA, Fisher MC (2006) The emerging amphibian pathogen Batrachochytrium dendrobatidis globally infects introduced populations of the North American bullfrog, Rana catesbeiana. Biol Lett 2:455-459

Johnson M, Berger L, Philips L, Speare R (2003) Fungicidal effects of chemical disinfectants, UV light, desiccation and heat on the amphibian chytrid Batrachochytrium dendrobatidis. Dis Aquat Org 57:255-260

Lips KR (1999) Mass mortality and population declines of anurans at an upland site in western Panama. Conserv Biol 13:117-125

Lips KR, Brem F, Brenes R, Reeve JD and 6 others (2006) Emerging infectious disease and the loss of biodiversity in a Neotropical amphibian community. Proc Natl Acad Sci USA 103(9):3165-3170

Longcore JE, Pessier AP, Nichols DK (1999) Batrachochytrium dendrobatidis gen. et sp. nov., a chytrid pathogenic to amphibians. Mycologia 91:219-227

McDonald KR, Méndez D, Müller R, Freeman AB, Speare R (2005) Decline in the prevalence of chytridiomycosis in upland frog populations in North Queensland, Australia. Pac Conserv Biol 11(2):114-120

Morehouse EA, James TY, Ganley ARD, Vilgalys R, Berger L, Murphy PJ, Longcore JE (2003) Multilocus sequence typing suggests the chytrid pathogen of amphibians is a recently emerged clone. Mol Ecol 12(2):395-403

Ouellet M, Mikaelian I, Pauli BD, Rodrigue J, Green DM (2005) Historical evidence of widespread chytrid infection in North American amphibian populations. Conserv Biol 19(5):1431-1440

Parris MJ, Baud DR (2004) Interactive effects of a heavy metal and chytridiomycosis on gray treefrog larvae (Hyla chysoscelis). Copeia 2004(2):344-350

Retallick RWR, McCallum HI, Speare R (2004) Endemic infection of the amphibian chytrid fungus in a frog community post-decline. PLoSci Biol 2(11):e351 doi:10.1371/journal. pbio. 0020351

Retallick RWR, Miera V, Richards KL, Field KJ, Collins JP (2006) A non-lethal technique for detecting the chytrid fungus Batrachochytrium dendrobatidis on tadpoles. Dis Aquat Org 72:77-85

Sredl MJ, Field KJ, Peterson AM (2003) Understanding and mitigating effects of chytrid fungus to amphibian populations in Arizona. Nongame and Endangered Wildlife Program Technical Report 208. Arizona Game and Fish Department, Phoenix, AZ

Stuart SN, Chanson JS, Cox NA, Young BE, Rodrigues ASL, Fischman DL, Waller RW (2004) Status and trends of amphibian declines and extinctions worldwide. Science 306:1783-1786

Woodhams DC, Alford RA, Marantelli G (2003) Emerging disease of amphibians cured by elevated body temperature. Dis Aquat Org 55:65-67 